\title{
On the Reform of Teaching College English at Different Levels
}

\author{
Liu Caiyun
}

Shandong Women's University, Jinan, Shandong 250002, China

\begin{abstract}
In recent years, teaching college English at different levels has attracted more and more attention. Conducting such a reform aims at resolving the individual differences among students and embodying the principle of "people-oriented" and teaching accordingly in order to improve teaching quality. The essay, based on the practice of graded teaching carried out in our college, analyzes its implementary background and presents the whole process and countermeasures we have taken.
\end{abstract}

Keywords - college English, graded teaching, practice and countermeasures

\section{浅谈大学英语分级教学改革}

\author{
刘彩云 \\ 山东女子学院, 济南, 山东, 中国
}

摘 要 近年来, 大学英语分级教学受到越来越多的关注。实施大学英语课程分级教学模式, 目的是解决学生中存在的个体差异, 体现以人为本、因材施教的原则, 以提高大学英语教学质量。本文分析了大学英语分级教学的实施背景, 依据《大学英语课程教学要求》 和当前教改形式，提出了分级教学方案以及存在的问题和对策。

关键词 大学英语, 分级教学, 实践与相应对策

\section{1. 引言}

2007 年教育部颁布的《大学英语课程教学要求》明确 规定：“大学英语教学应贯彻分类指导、因材施教的原则, 以适应个性化教学的实际需要。大学阶段的英语教学要求 分为三个层次，即一般要求、较高要求和更高要求。” 2009 年我校改制升本成功, 顺应社会发展需求, 培养外语优势 型人才成为了学校发展特色之一。大学英语教学部也在原 有专科教学经验的基础上, 针对《大学英语课程教学要求》, 从教学实践出发,对大学英语分级教学进行了有益的探索, 总结分级教学过程中出现的一些问题, 并在此基础上提出 了相应的对策。

\section{2. 大学英语分级教学的目的和意义}

我院招收的本科生是二本学生, 与重点大学和一本大 学相比, 学生来源受地区差异、城乡差异以及偏科等因素 的影响, 成分复杂, 水平参差不齐, 英语基础相对薄弱, 普遍存在语音、语法、词汇及文化知识不足的问题。

自 2006 年起, 全国大学英语四级考试采用了总分为
710 分的新题型, 较之旧题型本身难度加大, 其中学生感 觉最难的是听力, 其次是主观题分值的提升。阅读分值从 占总分的 $40 \%$ 降为 $35 \%$ ，而听力则从之前的 $20 \%$ 提高到 $35 \%$, 阅读由原来的多项选择变为多项选择题、选词填空 及信息匹配, 快速阅读变为多项选择+填空的结合体, 增加 了主观题, 翻译从句子翻译扩展为段落翻译, 分值提升至 $15 \%$, 这也加深了学生答题的难度, 可以说新题型对传统 课堂模式下的学生来说挑战不小。

面对这些情况, 如果继续采用传统专科教学模式, 即 统一的课型、教学进度、教学内容和一成不变的教材, 难 免会阻碍英语教学质量的全面提高。为了提高学生综合应 用英语的能力, 就必须以教育对象为本, 创新教学理念, 更新教学模式, 能适应新形势、行之有效的分级教学就应 运而生了。

\section{3. 大学英语分级教学的基本构想及模式、方法改革 分级就是本着因材施教, 提高教学效果的原则, 将学} 生划分为不同层次, 采取不同的教学手段和教学方法, 确 
定不同的培养目标, 力争经过一个阶段的学习后, 使每一 等级学生的英语水平在原有的基础上得到相应的提高。分 级教学能够满足不同层次外语水平学生的求知需要, 对于 基础好的学生, 着重培养其实际使用英语的交际能力, 对 于基础差的学生进行必要的补充训练, 逐步使学生都能达 到高要求。

\section{1 级别划分和课程安排}

非英语专业普通本科生新入校后, 参加学校统一组织 的大学英语分级考试, 参考高考成绩将学生分为 $\mathrm{A} 、 \mathrm{~B} 、 \mathrm{C}$ 三个层次, 每个英语教学班的学生拟定为 40 人左右, 每周 安排 2 个白天同时开课。

与学校实行学分制和现有课程体系保持一致, A、B、 $\mathrm{C}$ 三个级别的学生均要求四学期修满 12 学分。A 班学生前 三个学期进行基础英语教学, 为必修课, 第四学期开设高 级英语选修课, 如实用口语、写作、跨文化交际、英美文 化概况等。 B 班和 C 班的学生以正常教学进度修完大学英 语课程。

\section{2 教学内容、教学进度和教学模式}

针对三个级别学生的不同英语水平和学习需求, 任课 教师选择不同的教学内容, 采用不同的教学进度和教学模 式。A 级班实行研究性教学, 采用交际法, 启发式、互动 式等多种教学方式, 并结合多媒体和网络, 适当增加教学 内容和语言实践活动, 加快教学进度, 并对学生在自主学 习方面提出更高要求; $\mathrm{B}$ 级班采用常规课堂教学模式, 但 要改善教学方法, 提高课堂效率, 提高学生自主学习能力; $\mathrm{C}$ 级班教学活动以翻译和语法讲授为主, 授课的内容和语 言不能太难, 注重语言基础知识、基本技能的掌握。

\section{3 教学层次的调整}

按照 “以人为本” 的管理思想, 分级教学实行动态管 理, 以调动学生学习英语的主动性和积极性, 增强竞争意 识。充分尊重学生的个人意愿, 在分层教学分数线划定后, 需调换教学层次的学生必须本人提出申请, 经学生所在学 院和外语学院批准, 教务处备案后, 每个学期末根据学生 的平时学习状况、期末考试成绩及个人意愿进行级别动态 调整。

\section{4 学业测试与考核}

教学考核采用形成性评价和终结性评价相结合的方 式, 尤其要合理利用形成性评价。学期末的课程考试为终 结性评价, A、B、C 三个级别分别出题, 学生必须参加所
在级别的大学英语课程期末考试, 并记载到相应的课程成 绩中。

\section{4. 分级教学管理必须注意的几个问题}

\section{1 消除对学生的心理影响}

分级教学的等级是根据水平测试成绩和入学时的高考 英语成绩来确定的, 会有一定的偶然性, A 班学生有产生 优越感和自满心理而放松学习的可能; B、C 班学生会产生 自卑感, 自暴自弃, 甚至慢慢厌倦英语学习。因此, 要做 到科学合理分级。对于学生, 在分级前进行必要的宣传和 教育, 阐明分级教学并不是人为给学生 “分等级”, 而是 使所有学生在各自不同的起点上分别进步。要打消 B、C 级班学生的顾虑, 全身心地投入到学习中去。只有让学生 理解了这种教学及管理模式, 适应了竞争机制, 并产生积 极向上的心理, 教学才能顺利展开。

\section{2 加强教学管理及学生管理, 协调相关部门的关系}

分级教学给教学管理带来一系列问题。由于分级编班, 不同层次的班级来自不同的学院, 这样致使相关学院对学 生管理变得分散化, 且责任不明确。同时也加大了管理部 门对教学管理及学籍管理的难度, 尤其是分级教学过程中 的考试安排、成绩录入容易出现疏漏, 也加大了考务管理 人员的工作量。

推行分级教学管理的关键在于教学管理制度的完善, 课程编排时采用统一的模块; 考试组织管理要区别于其他 课程, 建立一套完善的分级教学考核体系; 成绩录入要逐 级审核, 避免出现疏漏。因此校方应认真加以研究和改进, 加强教学管理, 特别是协调相关部门的关系, 全校各学院 之间共同协调, 合理安排, 以便每周的英语课顺利进行。

\section{3 注意加大教师的培训力度}

大学英语师资队伍建设的力度和有效的激励措施直接 影响到教师对教改的态度和投入度, 这是教改能否成功的 关键。教师的培训首先是新的教育思想、教育理念的引导 与培训。其次是教学设计、教育技术、教学法、网络技术、 计算机辅助语言教学等方面的业务培训, 使教师具备教学 的信心与能力。此外, 学校应创造更多的机会让教师出国 观摩、培训和进修, 鼓励教师攻读硕士博士学位。与此同 时, 学校和院系领导应充分相信教师, 通过培训、学习以 及合理的激励机制调动教师的教改积极性和调控教师的教 学和科研投入, 使其对教师职业发展既有危机感, 又有自 信心。有这样的师资队伍, 教学改革就有希望, 成果就会 有保证。 


\section{4 学生考核标准}

考虑到学生的综合成绩测评和奖学金评定, 如果采用 不同的期末考试试卷, A 级班学生认为 $\mathrm{B} 、 \mathrm{C}$ 级的考试太 简单, 容易得高分; $\mathrm{B} 、 \mathrm{C}$ 级班的学生则认为自己在考试中 学到的东西不及 $\mathrm{A}$ 级班, 觉得不公平, 同时也不便于公平 合理的重新分班。而如果采用统一试卷考试后, 虽然可以 避免学生以上想法, 但却不利于真正衡量学生的实际水平 和教师的教学效果, 也违背了分级教学的初衷。因此这就 要求大学英语教研室根据教学要求和学生实际, 制定出比 较全面、客观、科学、准确的考试标准, 建立适应我校学 生实际水平的英语分级试题库等。

\section{5. 结束语}

英语分级教学是我校全面推行教育教学改革的一次大 胆尝试, 它充分体现了 “以人为本、分类指导、因材施教” 的原则。虽然不是什么新鲜事物, 却是一项系统和复杂的 工程, 涉及教师、学生、教材、教学管理等诸多方面, 在 具体实施过程中, 会遇到一些问题。因此, 应结合我校实 际情况, 大学英语教研室也会密切关注分级教学改革的整 个过程, 全力确保达到预定目标, 使学生最大限度地受益
于分级教学, 能在原有的基础上提高英语综合应用能力, 增强自主学习能力, 提高综合文化素养, 成长为外语优势 型专业人才, 全面推动我校大学英语教学改革。

\section{参考文献(References)}

[1] College English Teaching Syllabus (Revised Edition), Shanghai: Shanghai Foreign Language Education Press, 1999.

[2] College English Curriculum Requirements, Higher Education Department of Education Ministry, Beijing: Foreign Language Teaching And Research Press, 2007.

[3] Wen Qiufang, "New Ways of Reform in College English Teaching," Foreign Language Education in China, 2008(03).

[4] Huang Yuan-mei, "Analysis on the Practice of College English Level-based Teaching," Journal of East China Institute of Technology (Social Science), 2009, (01).

[5] Tan Wanmin, "Problems in Graded English Teaching of Newly-founded University and Solution - - Taking Bijie University as an Example" ,Journal of Bijie University, 2009, (01). 